\title{
INVESTIGATING THE IMPACT OF SPATIAL AUGMENTED REALITY ON COMMUNICATION BETWEEN DESIGN SESSION PARTICIPANTS - A PILOT STUDY
}

\author{
Giunta, Lorenzo (1); Ben Guefrache, Fatma (2); Dekoninck, Elies (1); Gopsill, James (1); O'Hare, \\ Jamie (1); Morosi, Federico (3)
}

1: University of Bath; 2: Université Grenoble Alpes; 3: Politecnico di Milano

\begin{abstract}
SAR provides an unobtrusive implementation of AR and enables multiple stakeholders to observe and interact with an augmented physical model. This is synonymous with co-design activities and hence, there is a potential for SAR to have a significant impact in the way design teams may set-up and run their co-design activities in the future. Whilst there are a growing number of studies which apply SAR to design activities, few studies exist that examine a particular element of a design activity in a controlled manner. This paper will begin to fill this gap through the controlled study of SAR and its effects on the communication between participants of a co-design activity. To do so the paper compares a controlled design session, using more traditional methods of design representations (3D models on a screen), to sessions run using SAR. The sessions are then analysed to gather information on the gestures used by the participants as well as the overall efficiency of the participants at completing the set design task. The paper concludes that the data gathered tentatively supports a link between the use of SAR and improved communication between design session participants.
\end{abstract}

Keywords: Augmented Reality, Spatial Augmented Reality, Collaborative design, Communication, Virtual reality

Contact:

Giunta, Lorenzo

University of Bath

Mechanical Engineering

United Kingdom

1g413@bath.ac.uk

Cite this article: Giunta, L., Ben Guefrache, F., Dekoninck, E., Gopsill, J., O’Hare, J., Morosi, F. (2019) ‘Investigating the Impact of Spatial Augmented Reality on Communication between Design Session Participants - A Pilot Study', in Proceedings of the 22nd International Conference on Engineering Design (ICED19), Delft, The Netherlands, 5-8 August 2019. DOI:10.1017/dsi.2019.203 


\section{INTRODUCTION}

Augmented Reality (AR) is a form of Mixed Reality; it occupies the space between Real and Virtual Environments on the Reality-Virtuality Continuum (van Krevelen and Poelman, 2010). In this space, AR is centre-left between the Real Environment and Augmented Virtuality (Figure 1).

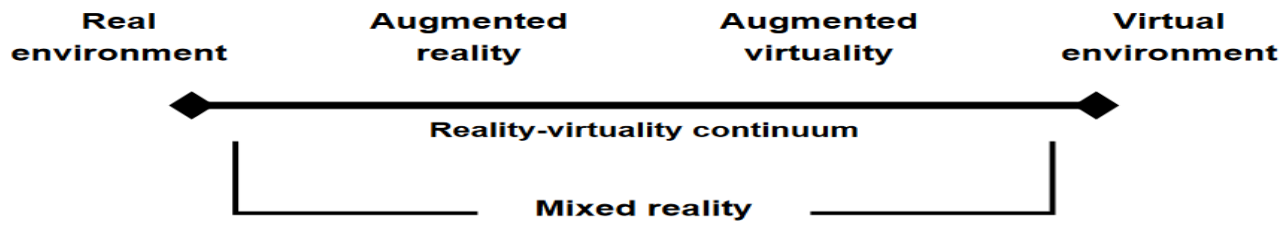

Figure 1. The Reality-Virtuality Continuum (Milgram and Kishino cited in van Krevelen and Poelman, 2010)

Various forms of AR exist and are usually categorised by their positioning relative to the user (e.g. head-worn, hand-held, or spatial) and then further subcategorised by the type of technology used to achieve augmentation (Bimber and Raskar, 2005). Unlike head-worn and hand-held AR, Spatial Augmented Reality (SAR) does not place the technology on the user, rather integrating it into their surrounding environment (Bimber and Raskar, 2005). While different technologies exist to achieve SAR, the most popular method is through the projection of images onto physical objects and is referred to as projective SAR. However, due to its popularity, the terms SAR and projective SAR are often used interchangeably (Furht, 2011).

This paper continues by presenting the related work in the application of SAR in design and the definition of co-design activities that will be used in this paper (Section 2). Section 3 describes the study that has been conducted to investigate whether differences exist between a SAR and non-SAR co-design activity. This is followed by the results, discussion and conclusions.

\section{RELATED WORK}

\subsection{Applications of SAR in design}

One of the hypotheses surrounding the application of SAR in design is that it will enable participants of a design session to communicate more effectively resulting in improved design outputs from a session. The number of design outputs has been investigated in part by O'Hare et al. (2018) who studied how SAR and AR technologies influence the novelty and quality of ideas in collaborative design sessions in comparison to traditional design sessions. It was revealed that SAR increased the novelty and quality of ideas, but also noted the challenges in setting-up and running the SAR platform consistently. This is corroborated by Akaoka, Ginn and Vertegaal (2010) whose study of SAR technology found that participants enjoyed the interaction environment it provided. The participants highlighted that SAR requires configuration to support the intended exercise and a single off-the-shelf implementation is not suitable for fully supporting the design activity. The interaction afforded by SAR has also been investigated by Porter et al. (2010) who evaluated the potential of SAR for User Interface design where finger tracking could be employed to indicate button presses. Their study revealed the mean "button-press time" increased by a factor of 1.2 for the participants using the SAR prototype when compared to the participants that made use of the standard prototype. However, the speed of iteration between prototypes was greatly reduced thereby enabling more iteration per timeframe. Participants again reported on the limitations of the technology, in particular the lack of tactile feedback in the SAR models. Participants nonetheless felt confident that SAR would be useful as a design tool. This is corroborated by the study run by Park and Moon (2013), conducted by applying AR technologies to design evaluation studies, which found that the primary hurdles faced by the implementation of AR technologies in design relate to: hand occlusions, interaction difficulties with the prototypes, and the weight and inherent discomfort of headsets. Giunta et al.'s (2018) review of the research investigating AR in design highlighted that much of the research has centred around the Concept, Preliminary Layout, and Definitive Layout stages, with gaps in the application of AR in early and late stages of the design process. Overall, the paper highlighted that the technology shows potential and that some commercial applications have been tried but that it still requires additional development before it can be considered mature enough. Supporting the development of AR by 
understanding how it affects design can lead to a better understanding of how it can be made ready for more widespread adoption.

\subsection{Co-design activities}

Co-design (Collaborative design) is a term without a perfectly agreed upon definition (Ulrich, Jo Anderson-Connell and Wu, 2003). Sanders and Stappers (2008) however attempted to clarify the matter proposing the definition of co-design as the application of collaborative creation during the entire design process. They state that co-design is "... collective creativity as it is applied across the whole span of a design process". While the importance of collaboration is well established as an approach to improve value creation for customers and users (Prahalad and Ramaswamy, 2004; Payne, Storbacka and Frow, 2008) the exact mechanism of action is less well defined.

\section{STUDY}

To investigate the effect of SAR on the communication behaviour between a client and designer, a controlled study has been developed to mimic a co-design activity. The key aim of this study is to identify whether there are significant differences in the number interactions within the design activity that uses a SAR or non-SAR set-up. If identified, then this paper will highlight the need for further research into the nature of this change through more in-depth analysis. This section continues by:

1. Describing the emulated co-design activity;

2. Detailing the experimental set-up and conditions along with the rationale in relation to how it enables researchers to investigate communication behaviour, in addition to;

3. The data capture and the subsequent post-processing of the data to provide insights into the communication behaviour discussed.

\subsection{The co-design activity}

The co-design activity to be emulated is one of a packaging design meeting involving one client and one designer, where the client is attempting to share their idea for the packaging to the designer. The designer will then try and create this idea within the packaging design software. In this scenario, it is often the case that a shared screen is used to show the design to the client.. To emulate this activity, the design sessions featured two participants, one representing the client and one representing the designer. The client was given a packaging design that only they can see; this represents their idea and acts as the final result they wish to achieve by the end of the design session. The designer was given a packaging design tool that only they can use within the session to create the design.

\subsection{Experimental set-up}

The experiments made use of two separate technologies: the SPARK platform and the "Observer" software, used to analyse the interactions between participants during design sessions (Ben-Guefrache et al., 2018). The SPARK platform was used to conduct the previously mentioned studies by O'Hare et al. (2018). Various validation studies conducted seem to support the utility of the platform both from a technological perspective and as a tool to support designers in real design sessions (Bellucci et al., 2018; Ben-Guefreche et al., 2018; O'Hare et al., 2018).

Figure 2 shows the two experimental set-ups for both the SAR (Figure 2a) and the traditional shared PC screen (Figure 2b), respectively. Each client is given a Target Model that is guarded from the designer's view. Each designer is given the packaging software, which is guarded from the client's view. The objective of the session was for the designer to accurately replicate the Target Model held by the client. To control the scenario further, the client was informed that they were not permitted to show the Target Model to the designer and the designer was informed that they were not permitted to show the interface of the tablet for editing the shared design representation. Video recordings were made of each session using three cameras; one per participant and one wide view camera to capture the scene as a whole (Figure $2 \mathrm{a}, \mathrm{b}$ ). 


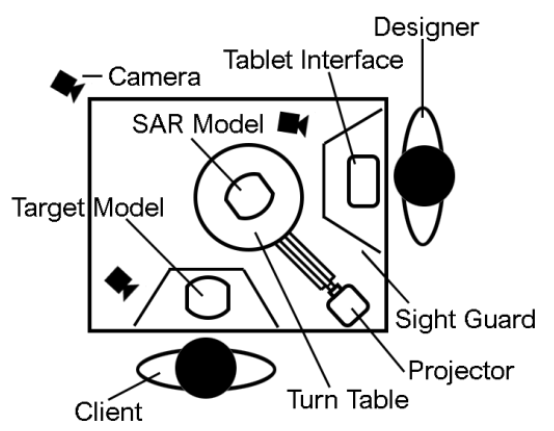

(a) $S A R$

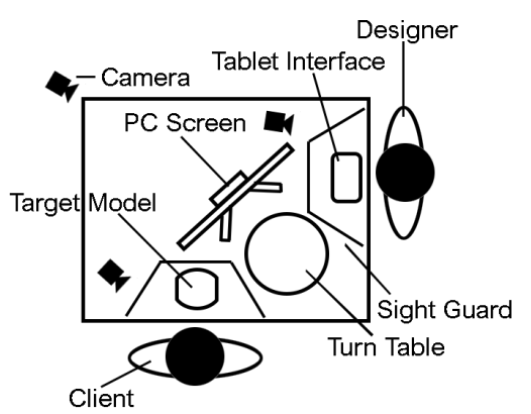

(b) Traditional

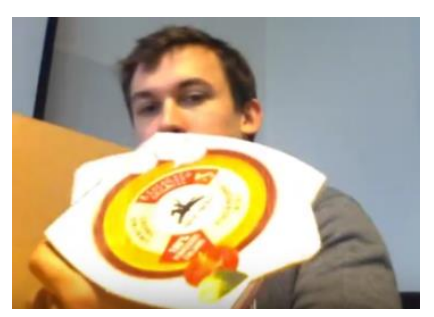

(c) Client looking at target model behind sight guard

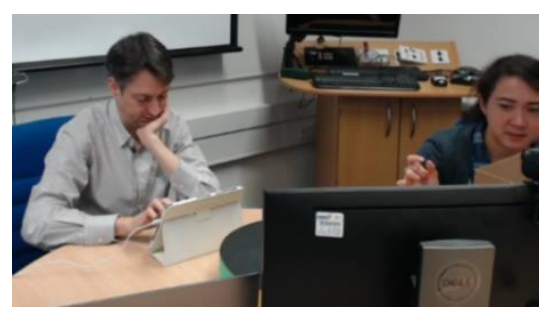

(d) Monitor condition. Monitor is seen in foreground behind it the turn table

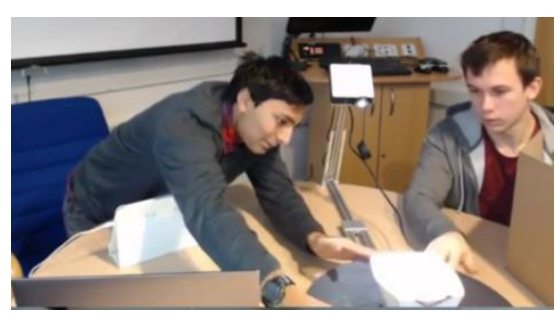

(e) SAR condition. Client and Designer in the process of turning turn table (SAR model appears white due to brightness disparity)

Figure 2. Schematics of experimental set-up (a-b) and implementation (c-e)

Figure 2(a, e) show the first experimental condition. The designer was provided with a tablet (Figure 3a) that controlled the SAR system that was placed between the designer and the client. The SAR system could be seen by both participants and was capable of projecting images onto a physical model fixed to the top of a turntable. When the turntable was rotated, the images projected appear to remain static in relation to the model itself through rotational tracking. Both client and designer were informed that they could interact with the turntable and the SAR model as they saw fit. The tablet the designer was provided with contained all the necessary digital art assets to successfully obtain the desired final result, as well as additional spurious art assets.

The second condition, shown in Figure 2(b, d), relied on a computer monitor to act as a shared design representation between the two participants. As with the SAR condition shown in Figure 2(a), the designer was provided with a tablet containing all the necessary art assets as well as additional unnecessary ones. Both the client and the designer could freely rotate the 3D model, to view it from different angles, about its y-axis using a turntable placed in front of the screen. Both participants were informed that they could interact with the model and the turntable as they saw fit. The experiment was controlled by keeping the target model and design software constant for all design sessions (Figure 3).

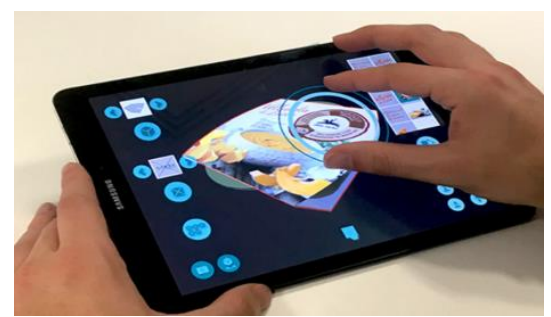

(a) Tablet Interface used by "Designer" (Morosi et al., 2018)

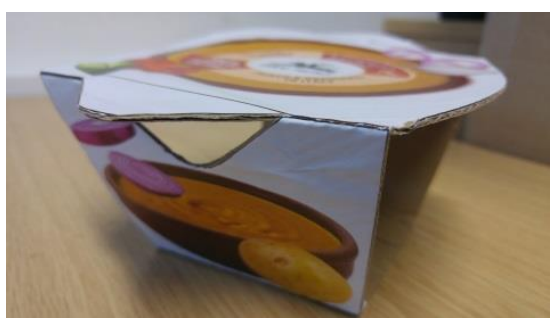

(b) Target Model used by "Client"

Figure 3. Items provided to "Designer" and "Client"

Due to the reuse of assets and the final design to be recreated, participants were only permitted to join one design session (to avoid potential learning effects). Additionally, at the start of each session, the designer was allowed some time to familiarize themselves with the tablet interface that would be used 
to manipulate either the SAR model or the 3D representation. The amount of this practice time provided was not a set amount but rather until the designer felt comfortable using the interface. A different model with different assets were used.

\subsection{Data processing and analysis}

To identify whether there are significant differences in the interactions within the design activity that uses a SAR or non-SAR set-up the communication transactions between the client and designer were examined. The framework defined by Ben-Guefrache et al. (2018) was used to give insight into the types of interactions occurring between the session's participants. The efficiency of communication analysis involves the examination of the overall time taken to complete the session. These two techniques are now discussed.

\subsubsection{Interaction analysis}

The scientific literature has studied the interactions in design and co-design sessions through different means and has predominately relied on the protocol analysis method (Cross, Christiaans and Dorst, 1996). Protocol analysis is based on the analysis of verbalisations and/or the gestures associated with these verbalisations.

In order to understand the design practice that occurs in co-creative sessions, the different typologies of interactions between participants need to be observed and analysed. The interaction centric framework (Ben-Guefrache et al., 2018) is based on the capture of (non)verbal interaction between the participants and the materials used in the session (physical prototypes, digital, etc.). The use of a metaanalysis such as this is more appropriate for a scoping study, such as that presented in this paper, due to the simplicity of the implementation, which offers considerable savings in manpower and time that would otherwise be needed to transcribe (and potentially translate) each session. Furthermore, the (non)verbal interactions can provide an approximation of the number of communication transactions that occur in the session.

The coding scheme is based on three elements: the client(s) and the designer(s) who are the Actors, and the interaction(s) that occur between them. The interactions that can occur between the Actors can be classified as: Verbal, Digital, Mixed; or Ephemeral (Figure 4). The analysis of the participants' interactions provides insight into the ability of the client and the designer to effectively share ideas and move closer to the desired final result.

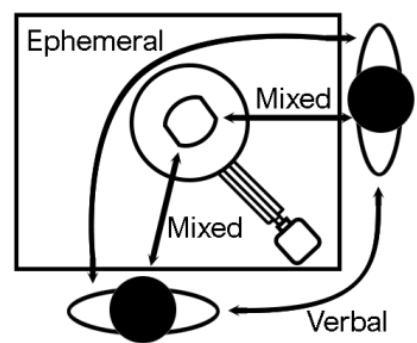

(a) Interactions Present in SAR Session

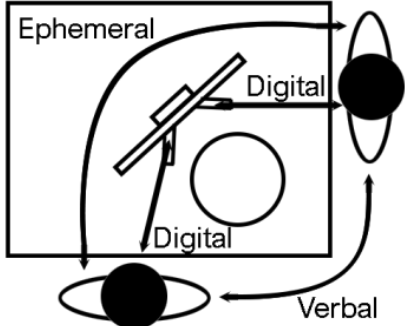

(b) Interactions Present in Traditional Session

Figure 4. Interaction analysis framework

The four types of interactions are shown in Figure 4. Coding of each interaction begins when either participant displays one of the following behaviours whilst simultaneously speaking with their counterpart:

The 'Verbal' interaction between the participants is a type of interaction that is not supported by any other means. That is to say that the participant only speaks but does not rely on any other medium to communicate.

The 'Digital' interaction category includes any kind of representation displayed on a screen, such as a presentation on personal laptop, tablet or any information shared from phones.

The 'Mixed' interaction is described as including a physical prototype (physical mock-up with a predefined shape, mostly 3D printed) on which digital elements like pictures, images, textures or text are projected through the mean of a SAR system. It should be noted that that the act of manipulating the tablet interface (which controls the SAR/PC Screen system) is considered as a mixed interaction. 
Finally, 'Ephemeral' refers to interactions that include gesticulation used instead of, or while, speaking with the purpose of communication. In addition, gestures made in the air made in order to mimic form or explain an idea are included. The person making the gesture can depict or mimic an object (shape, volume, surface), a usage (function in a specific context) or a behaviour (deformation of an object, simulate flashing lights etc.).

The interactions were captured through the on-the-fly method, which aims to provide a quantitative description of the interactions made by the participants (designers and clients) during a co-creative design session. The on-the-fly method involves two phases: first, two coders in the experiment room code the live session. One is charged with the identifying the actor (designer or client) who has initiated the interaction and a second coder identifies which type of interaction (Verbal, Digital, Mixed, or Ephemeral) occurred. This is done through the use of a software tool called 'Observer' and coders are trained in advance from a coding book which provides a set of coding rules (Ben-Guefrache et al., 2018). The second phase is dedicated to the analysis of the data gathered during the session in order to obtain a quantitative representation of the interactions that occurred during the co-design session. This is done by analysing the percentages of interactions initiated by the designer and client as well as the percentages of the types of interactions.

\subsubsection{Efficiency of design activity}

In addition to interaction analysis, the efficiency of the design activity was also assessed through a comparison of the time taken to complete the activity for each condition. The start of the session was taken to be when either participant began speaking to the other about the design task. The end point of the session was when the client determined that the representation (either the digital 3D representation or the SAR model depending on the condition being tested) was sufficiently close in appearance to the model they held. No specific margin of error was set for the participants to have to fall within, but the observer present in the room checked for completeness and type of art assets used. The times for each session were then presented as a box-and-whisker plot to better illustrate the differences in time taken between the two conditions. Due to the controlled nature of the study, the only barrier to successfully completing the activity was the ability of the client to successfully communicate the design of the target model to the designer and the designer's ability to interpret and query these instructions. It then stands to reason that, the time taken to complete the task would be indicative of the ease with which the participants were able to communicate their intentions.

\section{RESULTS}

Fourteen participants were recruited for the experiments for a total of seven sessions. Of the seven, four sessions were undertaken using the SAR model and three used the 3D digital representation (Table 1). In all but one session, participants managed to accurately replicate the model provided. SAR-02, which used the SAR representation, selected a similar, yet incorrect, version of one of the logos. This can be attributed to the low quality of the image projection on the top surface of the SAR representation which made it difficult for the participants to read the text and identify that the logo they had selected, while the same shape, size, and colour, had different text. It should also be noted that SAR-04 was omitted from the interaction analysis due to a limitation in the coding methodology as the participants began to use pen and paper to support the design session. While this has no great impact on the efficiency results, the interaction analysis cannot differentiate between this type of interaction and the interaction with the physical model by the client. Lastly, it should be noted that some of the sessions suffered from interruptions due to technological difficulties. During these interruptions, while the platform was reset, the session was halted and the timing paused.

\subsection{Participants}

Participants were recruited from the Faculty of Mechanical Engineering and Faculty of Electrical Engineering. All participants fulfilling the role of designer had experience with Computer Aided Design (CAD). No assessment was made as to the participants' knowledge or competence but only students in postgraduate or final year bachelors were permitted to participate, guaranteeing some level of competence. 


\subsection{Interaction analysis}

Figure 5 shows the percentage of interactions initiated by designers and clients within each session in order to evaluate and compare their participation. Clients perform a higher percentage of the interactions in all three SAR sessions (84-94.2\%) with designers initiating between 5.8\% and 16\%. These results are to be expected because the scenario places a considerable emphasis on the client's ability to communicate the contents of the target model to the designer.

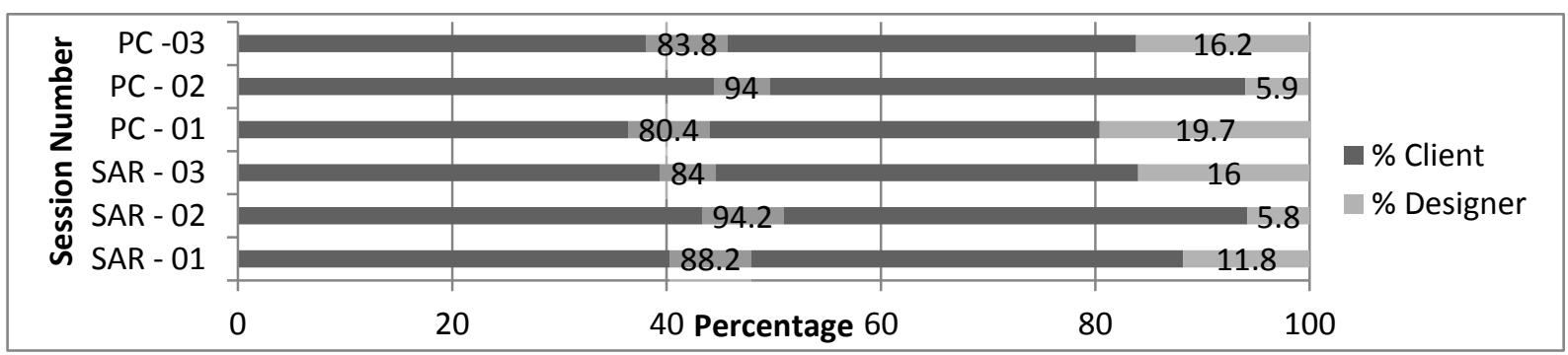

Figure 5. Interactions initiated by client or designer for traditional $(P C)$ and SAR Sessions

The proportions of each interaction type in each session are calculated in Figure 6. In both the SAR and PC sessions the majority of the interaction took place using the shared model representation; this can be seen by the majority of the interactions being mixed (for SAR sessions) and digital (for the PC sessions). It should be noted that a higher percentage of mixed interactions for all SAR sessions (56 to 63\%) when compared to the digital interactions for the PC sessions. This is an encouraging result that demonstrates the salience of the mixed interactions during these sessions. Furthermore, there is a not insignificant use of verbal interactions. This accounted for up to $29 \%$ of the total interactions in the SAR sessions and $38 \%$ in the PC sessions. This discrepancy may potentially be explained by the decreased support that the PC provides when compared to the SAR system, forcing the participants to rely on describing in greater detail their desired results. Gesturing in the air (ephemeral interactions) is significant in both conditions and, as in the other experiments (O'Hare et al., 2018), appears to be used as a way of actively expressing ideas and support during the discourse.

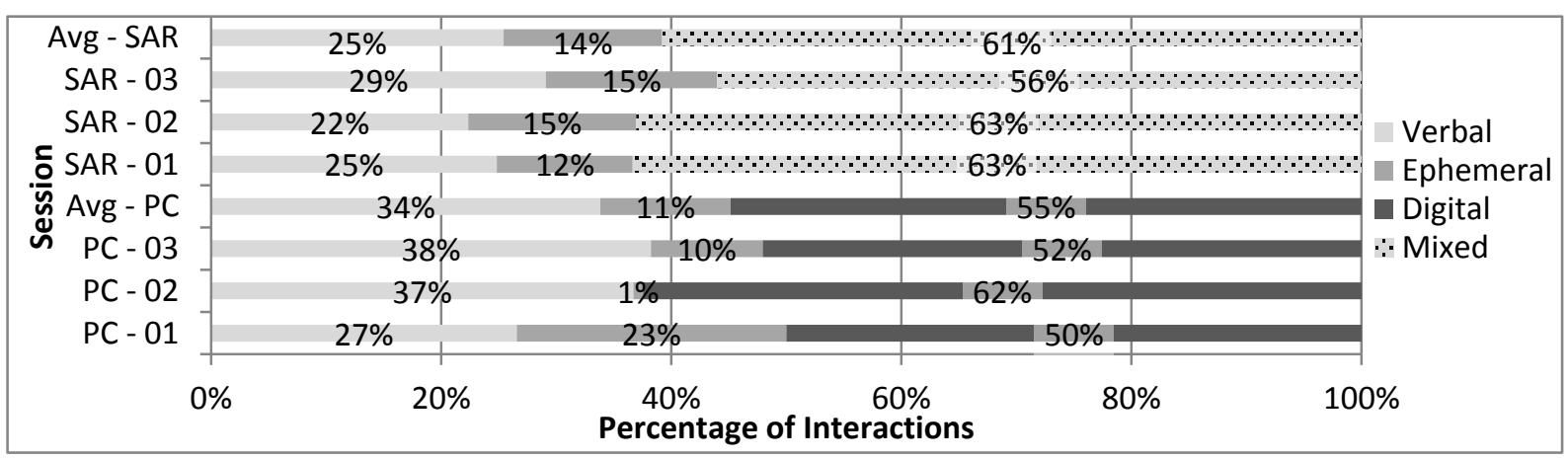

Figure 6. Proportion of each interaction type for SAR and traditional (PC)

\subsection{Efficiency of process}

Table 1 shows the time taken for each session to be completed as well as the experimental condition. Figure 7 consolidates this information into a box-and-whisker diagram. As can be seen from Figure 7 the mean time taken for SAR condition sessions was lower than that of the PC condition sessions by 6 minutes and 8 seconds. Figure 7 also shows that there is relatively little overlap between the SAR and PC sessions. Increasing the sample size may show a more significant divergence between the two, further highlighting the impact of SAR. 
Table 1. Time Taken and Number of Interactions for Each Session and Condition

\begin{tabular}{|c|c|c|c|c|c|c|c|}
\hline & \multicolumn{4}{|c|}{ SAR } & \multicolumn{3}{|c|}{ PC } \\
\hline \multirow{5}{*}{$\begin{array}{l}\text { Session Number } \\
\text { Time Taken } \\
\text { Mean } \\
\text { Median } \\
\sigma\end{array}$} & 01 & 02 & 03 & 04 & 01 & 02 & 03 \\
\hline & $9: 52$ & $23: 41$ & $21: 12$ & $16: 39$ & $26: 38$ & $17: 15$ & $28: 03$ \\
\hline & \multicolumn{4}{|c|}{$17: 51$} & \multicolumn{3}{|c|}{$23: 59$} \\
\hline & \multicolumn{4}{|c|}{ 18:56 } & \multicolumn{3}{|c|}{$26: 38$} \\
\hline & \multicolumn{4}{|c|}{ 06:04 } & \multicolumn{3}{|c|}{ 05:52 } \\
\hline
\end{tabular}

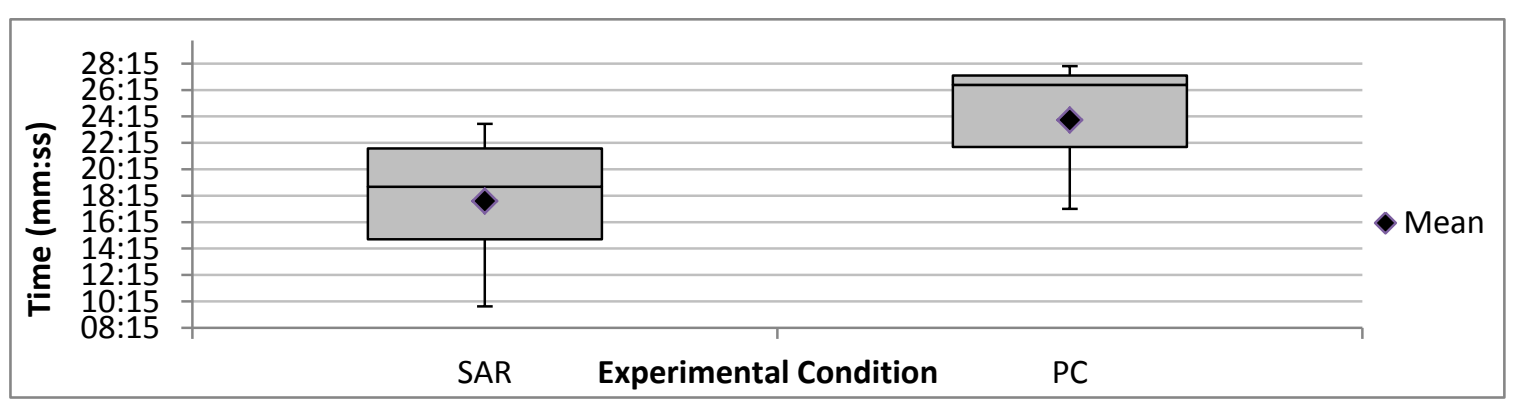

Figure 7. Comparison of time taken to complete task

\section{DIscussion}

The results of the efficiency of the process analysis lend credence to the claim that SAR does indeed facilitate the communication of ideas between design session participants. The controlled nature of the task implies that, to successfully complete it, participants must be able to communicate efficiently. It then stands to reason that a reduction in the time taken to complete the task reflects an improvement in the ability of the participants to communicate with one another. The results from the interaction analysis seem to tentatively suggest that the use of SAR supports improved communication between participants as the percentage of interactions involving the shared design representation is higher when using SAR. Due to the small sample size involved in this pilot study neither the efficiency of the process, nor the interaction analysis, provide conclusive or strong evidence of the superiority of SAR over the PC system. However, when taken together the two analyses provide some support to the theory and certainly suggest that more research is warranted. In addition, one unexpected result was noticed during the interaction analysis. Interestingly the percentage of ephemeral interaction remains similar between PC and SAR sessions, but the amount of verbal interaction increases in the PC sessions. This seems to support the theory that the client does not compensate for the lack of support the PC screen offers in communicating their ideas to the designer by using hand gestures but rather relies more on verbal cues. This potentially could also lend credence to the claim that SAR better supports the communication between the participants.

The limitations encountered in this study such as the failure of SAR-02's participants to select all the correct assets is in of itself not a major issue, as the asset they selected was very similar in appearance and had the correct scale and rotation. It is possible that this issue may have been caused by miscommunication between the participants. However, it betrays a more serious underlying problem: the user interface on the tablet and the resolution of the projector is deficient and causes the participants to make simple mistakes. Having the participants fill in a System Usability Score (SUS) after completing their session could shed more light into their confidence in using the platform. As the poor user interface was mentioned by many of the designers in the post session discussions as a point of frustration a SUS would allow for normalizing the results across different sessions. Furthermore, the SPARK platform suffers from stability issues. This adds to the frustration of the participants and also affects the quality of the research data produced as the participants are forced to stop the session, interrupting their workflow. Fortunately, the majority of these issues are a matter of implementing fixes to the technology in use and have not highlighted an underlying issue with the strategy of using SAR in design.

The methodology implemented did perhaps not implement all the controls needed. One element that was not captured was the variance between clients' existing communication skills, as this influences their ability to more effectively guide the designer. 


\subsection{Future work}

The small sample size used in this study has precluded the ability to draw firmer conclusions from the data analysed. As such it would certainly be advantageous to repeat the study with a larger sample size. Furthermore, as mentioned, future sessions should attempt to gauge the ability of the participants to communicate effectively and be able to adjust for this when evaluating the results. Additionally as there were issues with SAR-02 and SAR-04, the methodology for giving the participants instructions on what is expected of them in the session should be updated to guarantee that they are fully aware that they must review their final work and that they should rely only on the tool provided to them. Some additional method of checking the accuracy with which they replicate the design may also be warranted. The surprising result that the number of ephemeral interactions does not increase between sessions types, while verbal interactions do, also suggests that closer attention should be paid to analysing the richness of communication between the participants to analyse not just the number or type of interaction but also the amount of data transmitted between the participants during each interaction.

One type of analysis that was not performed during this study was log analysis. The possibility of analysing the rework done by the designer to achieve the client's demands becomes available. Gopsill et al. (2016) suggests that the use of CAD logs can be a good source of large amounts of quantitative data that can be used to determine position, rotation, scale, etc. of art assets. The large data sample would enable more sophisticated analysis of the session efficiency from primary data and create the possibility to record the type of workflow chosen (e.g.: working on one asset at a time versus placing and adjusting multiple simultaneously).

Additionally, gaze analysis was not performed in this study as the interaction analysis was deemed sufficient. However Boa and Hicks (2016) provide a solid methodology for approaching gaze analysis that might prove to be a valuable addition to supplement the data obtained through the use of interaction analysis. Of particular interest would be to cross reference the type of interaction occurring with where the participants focus their gaze.

In addition to techniques that could be used to expand on the data collected, it is important to focus on the expansion of the scope of the study. The methodology implemented seems to have proven effective and it now becomes necessary to expand into exploring how the communication between participants is affected in design sessions with more variables and a more naturalistic design challenge.

\section{CONCLUSION}

This study set out to analyse whether SAR can support communication between design session participants more effectively when compared to more traditional design representations (i.e. 3D models on a screen). The paper showed how the mode of interaction between participants is affected by the type of technology used.

In conclusion, this study appears to provide some credence to the claim that SAR looks promising for co-design sessions by supporting the communication between participants. Sessions using SAR were noticeably shorter than sessions run using a 3D digital representation on a PC screen. The percentage of interaction between participants with the shared design representation was also higher in the SAR scenarios than in the 3D model scenarios indicating that the SAR system better supports communication in the shared space. Clients in 3D model sessions had to rely more on the use of verbal cues to guide the designer to compensate for this. This may also be linked to the amount of data that can be transmitted between participants during the each interaction: with the SAR model supporting larger amounts of data transmitted. Lastly, this study shows that the methodology applied is a valid approach for the investigation of the influence SAR has on communication between design session participants.

\section{REFERENCES}

Akaoka, E., Ginn, T. and Vertegaal, R. (2010), "DisplayObjects: Prototyping Functional Physical Interfaces on 3D Styrofoam, Paper or Cardboard Models", in Proceedings of the fourth international conference on Tangible, embedded, and embodied interaction - TEI '10. ACM Press, New York, New York, USA, p. 49. http://doi.org/10.1145/1709886.1709897. 
Bellucci, G., Becattini, N., Cascini, G., O’Hare, J., Majoral, X., Boujut, J.-F. and Ben-Guefrache, F. (2018), D5.1 validation at end users' premises. Available at: http://spark-project.net/sites/default/files/filewp/D5.1_WP5_Validation at end-users premises.pdf.

Ben-Guefrache, F., Masclet, C., Prudhomme, G., Cascini, G. and O’Hare, J. A. (2018), "Real-Time Coding Method For Capture Of Artefact-Centric Iinteractions In Co-Creative Design Sessions", in International Design Conference - Design 2018, pp. 33-44. http://doi.org/10.21278/idc.2018.0468.

Ben-Guefreche, F., Boujut, J.-F., Masclet, C., Poulin, M., Prudhomme, G., Becattini, N., Carbone, N., O’Hare, J., Giunta, L., Dekoninck, E. and Cascini, G. (2018), Results of the experiments benchmarking the platform. Available at: http://spark-project.net/sites/default/files/file-wp/D4.2_WP4_Results_of_the_ experiments_benchmarking_the_platform.pdf.

Bimber, O. and Raskar, R. (2005), Spatial Augmented Reality Merging Real and Virtual Worlds. A K Peters, Wellesley

Boa, D. R. and Hicks, B. (2016), "Discriminating engineering information interaction using eye tracking and an information operations model", in Proceedings of International Design Conference, DESIGN 2016, pp. 1-10.

Cross, N., Christiaans, H. and Dorst, K. (1996), Analysing design activity. Wiley, New York, New York, USA.

Furht, B. (ed.) (2011), Handbook of Augmented Reality. New York, NY: Springer, New York. http://doi.org/10.1007/978-1-4614-0064-6.

Giunta, L., Dekoninck, E., Gopsill, J. and Hare, J. O. (2018), “A Review of Augmented Reality Research for Design Practice : Looking to the Future", in NordDesign 2018. Available at: https://www.designsociety.org/publication/40967/A+Review+of+Augmented+Reality+Research+for+Desi gn+Practice $\% 3 \mathrm{~A}+$ Looking+to+the+Future.

Gopsill, J., Snider, C., Shi, L. and Hicks, B. (2016), "Computer aided design user interaction as a sensor for monitoring engineers and the engineering design process", in Proceedings of International Design Conference, DESIGN 2016, pp. 1707-1718.

van Krevelen, D. W. F. and Poelman, R. (2010), “A Survey of Augmented Reality Technologies, Applications and Limitations", The International Journal of Virtual Reality, Vol. 9 No. 2, pp. 1-20.

Morosi, F., Carli, I., Caruso, G., Cascini, G., Dhokia, V. and Ben-Guefrache, F. (2018), “Analysis of Co-Design Scenarios and Activities for the Development of a Spatial-Augmented Reality Design Platform", in International Design Conference - Design 2018, pp. 381-392. http://doi.org/10.21278/idc.2018.0504.

O’Hare, J. A., Dekoninck, E., Giunta, L., Boujut, J. and Becattini, N. (2018), "Exploring the Performance of Augmented Reality Technologies in Co- Creative Sessions : Initial Results From Controlled Experiments", International Design Conference - Design 2018, pp. 405-416. http://doi.org/10.21278/idc.2018.0391.

Park, H. and Moon, H.-C. (2013), "Design evaluation of information appliances using augmented reality-based tangible interaction", Computers in Industry. Elsevier B.V., Vol. 64 No. 7, pp. 854-868. http://doi.org/10.1016/j.compind.2013.05.006.

Payne, A. F., Storbacka, K. and Frow, P. (2008), "Managing the co-creation of value", Journal of the Academy of Marketing Science, Vol. 36 No. 1, pp. 83-96. http://doi.org/10.1007/s11747-007-0070-0.

Porter, S. R., Marner, M. R., Smith, R. T., Zucco, J. E. and Thomas, B. H. (2010), "Validating spatial augmented reality for interactive rapid prototyping”, in 2010 IEEE International Symposium on Mixed and Augmented Reality. IEEE, pp. 265-266. http://doi.org/10.1109/ISMAR.2010.5643599.

Prahalad, C. K. and Ramaswamy, V. (2004), "Co-creation experiences: The next practice in value creation", Journal of Interactive Marketing. Elsevier, Vol. 18 No. 3, pp. 5-14. http://doi.org/10.1002/dir.20015.

Sanders, E. B.-N. and Stappers, P. J. (2008), "Co-creation and the new landscapes of design", CoDesign, Vol. 4 No. 1, pp. 5-18. http://doi.org/10.1080/15710880701875068.

Ulrich, P. V., Jo Anderson-Connell, L. and Wu, W. (2003), "Consumer co-design of apparel for mass customization", Journal of Fashion Marketing and Management: An International Journal, Vol. 7 No. 4 , pp. 398-412. http://doi.org/10.1108/13612020310496985.

\section{ACKNOWLEDGEMENTS}

The work reported in this paper was completed as part of the SPARK project, which has received funding from the European Union's Horizon 2020 research and innovation programme under grant agreement No.688417. This paper reflects only the authors' views and the European Commission is not responsible for any use that may be made of the information it contains. 